\title{
The effects of sports on university students' continuous anger and anger sub-levels
}

\author{
Oksay OGUZ, Ahmet Gursel OGUZ
}

Faculty of Sport Sciences, Selçuk University, Turkey.

Correspondence address to A. G. Oguz, e-mail; agoguz@selcuk.edu.tr

\begin{abstract}
In this study, the effect of sports on the anger levels of university students was examined. The study group consisted of 101 male and 99 female students studying at Selçuk University. The continuous anger levels of the individuals who do and do not sports participate in the study were determined by the "Continuous Anger Subscale" of the Continuous Anger - Anger Expression Scale Scale, which was adapted to Turkey by Özer. To analyses data, the independent t-test and ANOVA were conducted. According to the data of 18-20 (40 students), 21-23 (126 students), 24 years and over (34 students); The difference between the two groups who do and do not sports was important for the continuous anger subscale score as a result of two independent sample $t$ tests $(\mathrm{p}<0.05)$. According to this, the score of the anger subscale is higher than that of the individual who does not perform. The $\mathrm{p}$ - value for anger subscale score was found to be significant $(\mathrm{p}<0.05)$. According to this, the individual who plays sports has a higher score on the subscale of anger than the individual who does not. Sports has played an active role in the suppression of the anger as the university student's constantly raising the level of anger. P value for anger subscale score of independent two-sample T-test for testing whether male and female subjects had significantly different scores of continuous anger subscale scores $(\mathrm{p}<0.05)$. According to this, the score of the male individual is higher than that of the female anger. It can be said that men can express their anger more easily than women. There was a significant difference between the father professions $(\mathrm{p}<0.05)$ for the continuous anger subscale scores. The scores of the continuous anger subscale scores of the private sector and the self-employed individuals of the father occupation were the same, while those of the father sector occupation were lower than the scores of the continuous anger subscale of the public sector. These results show that while the anger of the individuals whose father is the private sector and self-employed remains at the same level, the levels of continuous anger of the individuals working for the father in the public sector are found to be low.
\end{abstract}

Keywords: Anger level, university student, adolescents, athletes, non-athletes.

\section{INTRODUCTION}

Adolescence is the period in which the individual begins to develop during the childhood period and reaches physiological maturity (13).

Adolescence is a difficult life for a developing child. After a period of fairly long and balanced behavior, the child suddenly goes into adulthood, an unstable and disordered stage $(18,27)$.

The cause of this variable emotional state seen in adolescents may be due to the lack of satisfying a basic need, the lack of satisfying, and the adolescent tries to express himself in some way. When these wishes and needs are met positively, the teenager is happy, otherwise they are worried and show different emotional reactions (27).

In everyday life, the individual faces many different situations based on human relations. While some of these situations bring out desirable and positive feelings such as joy, laughter, laughter, and others, they can cause unwanted and negative emotions such as anxiety, sadness and frustration due to obstacles, conflicts and problems caused by them. These negative emotions can affect the life of the individual in a positive way. One of the emotions experienced by the individual is anger sentiment (4,7$9,11,12,14,19,28)$.

Anger is caused by interactions between people and is a feeling that is experienced when an individual's plans, wants and needs are obstructed, and he perceives injustice, injustice and threat to his / her own self $(2,10,12)$.

The feeling of anger also differs in terms of expression. Individuals may show their anger in the form of throwing, directing and controlling. 
Throwing bribery involves keeping the anger under pressure and not expressing it; as well as verbal such as profanity, insult, criticism as well as physically manifesting such as being outwardly directed and damaging to objects. Control of the pupil is usually patient, calm, tolerant and understanding in relation to others and often controlling and calming the anger tendency $(17,23)$.

Anger emerges in different forms in individuals. These; an inner appearance of the anger, outer appearance of the anger and anger control $(6,15,17,24-26)$.

Outrageous outburst; is an adaptive response to the stress that is caused by the anger. Anger; is an alternative mechanism of adjustment that is used against the factors of anger that exist by hiding or angering someone. Anger control is the control experience that expresses anger with individual reactions, to the extent that one controls the anger in relation to others, or tends to calm down to what extent (24).

Anger is one of the important emotions in human life. It can be thought that it is important to express anger and anger in relation to the stress coping and problem-solving approaches of the individual when expressing anger and anger are thought to be a stress and problematic situation mainly caused by interpersonal problems. For this reason, it is important to recognize and understand the anger well, and in the direction of these determinations, school health can play a key role in early detection of mental and physical problems in improving adolescents' ability to cope appropriately. In this study, the effects of self-esteem, continuous anger and anger expression styles and individualfamilial demographic characteristics of university students who do sports and do not play sports are being investigated.

\section{MATERIALS \& METHODS}

\section{Research Model and Sample}

This study was conducted in accordance with the general screening model. The research universe of the research consists of students who are studying at the Faculty of Agriculture, Faculty of Medicine and Faculty of Sports Sciences of Selçuk University. The study group of the study consists of 200 students studying at university. Of the students participating in the survey, 99 are female and 101 are male. Students are between 18 and 24 years old.

\section{Data Collection Tools}

\section{Continuous Anger and Anger Expression Scale}

Spielberger and colleagues developed the scale of continuous anger and anger expression. Translation to Turkish and adaptation work was done by Özer. The first ten items of thirty-four items measure the level of constant anger, while the other twenty-four items determine the way an individual expresses anger. The scale is a quadrant Likert type measurement. Internal consistency coefficients calculated from the scale; seventy-nine for constant anger dimension, eighty-four for control anger, seventy-eight for anger out and sixty two for anger suppression.

High scores from the Continuous Anger Subscale indicate that the level of anger is high, the high scores in the Anger Inside Scale show that the anger is suppressed, The high scores on the Anger Out Scale show that the anger is easily expressed, The high scores on the Anger Control Scale show that the anger can be controlled (21).

\section{Data analysis}

The normal distribution fitness test for the data was also tested using the Kolmogorov-Smirnov test, again using the plate test for variance homogeneity. In order to apply parametric tests, both normal distribution fitness and variance homogeneity are required at the same time. Non-normal distribution of data and non-homogeneous variance of the data requires using non-parametric tests. ANOVA (Oneway ANOVA) test for more than two groups from the parametric tests and independent two-sample $\mathrm{T}$ test for independent two groups were used for the analysis of the Kolmogorov- Smirnov test and the leaf test. In the analysis of the data, SPSS 15 Statistical Package Program was used.

\section{RESULTS}

$101(50.5 \%)$ of the students did not play sports, $99(99.5 \%)$ did not play sports and the majority (63\%) were in the age range of 21-23 years in the demographic information of the subjects participating in the research $(79.5 \%)$ and primary school graduates $(67 \%)$, while the majority of the income level (82\%) was moderate.

Continous anger subscale and anger subscale scores were found significant difference between groups $(p<0.05$; Table 2$)$. For both variables, individuals who do sport had higher scores than individuals who do not sport. On the other hand, 
there was no significant difference between groups in anger outward subscale and anger control subscale scores $(\mathrm{p}>0.05)$.

Table 1. Demographic data.

\begin{tabular}{llcc}
\hline & & $\mathrm{n}$ & $\%$ \\
\hline Satatus & Sports & 101 & 50.5 \\
Gender & Non-sports & 99 & 49.5 \\
Age & Male & 101 & 50.5 \\
& Female & 99 & 49.5 \\
Number of Siblings & $18-20$ & 40 & 20.0 \\
& $21-23$ & 126 & 63.0 \\
& 24 and above & 34 & 17.0 \\
Education Status & 1,00 & 81 & 40.5 \\
& 2,00 & 87 & 43.5 \\
& 3,00 & 32 & 16.0 \\
Mother Profession & Primary School & 8 & 4.0 \\
& High School & 10 & 5.0 \\
& University & 182 & 91.0 \\
Father Profession & Housewife & 159 & 79.5 \\
& Public & 20 & 10.0 \\
& Private & 21 & 10.5 \\
& Self Employment & 82 & 41.0 \\
Mother Education & Public & 70 & 35.0 \\
& Private & 48 & 24.0 \\
& Primary School & 134 & 67.0 \\
& High School & 47 & 23.5 \\
Father Education & University & 19 & 9.5 \\
& Primary School & 94 & 47.0 \\
& High School & 56 & 28.0 \\
& University & 50 & 25.0 \\
& Low & 18 & 9.0 \\
& Intermediate & 164 & 82.0 \\
& High & 18 & 9.0 \\
\hline
\end{tabular}

Scores of male and female was not different for continuous anger subscale, anger subscale, and anger control subscale $(p>0.05)$. Beside, anger outward subscale scores in male individuals was higher than female $(\mathrm{p}<0.05)$.

Anova, which conducted to compare the anger levels of age groups, revealed that there were no significant difference in scores of continuous anger subscale, anger subscale, anger outward subscale, and anger control subscale between age groups ( $>0.05$; Table 4).

Table 5 presents the comparisions of anger scores for number of siblings. No significant difference was found between groups in scores of continuous anger subscale, anger subscale, anger outward subscale, and anger control subscale $(\mathrm{p}>0.05)$.

Table 5 shows the comparisions of anger scores for number of siblings. There was no significant difference between groups in scores of continuous anger subscale, anger subscale, anger outward subscale, and anger control subscale ( $p>0.05)$.

As seen in Table 7, Anova did not reveal any significant difference between mothers' professions in all subscales $(\mathrm{p}>0.05)$.

Table 8 shows comparisions subscales according to the fathers' professions. The results of Anova revealed that anger subscale, anger outward subscale, and anger control subscale had similar scores for father's profession variable $(p>0.05)$. On the other part, continuous anger subscale scores was found significantly different for father's profession variable $(\mathrm{p}<0.05)$.

Table 2. Difference between sports status and scales.

\begin{tabular}{llccccc}
\hline & & $\mathrm{n}$ & Mean & $\mathrm{SD}$ & $\mathrm{T}$ & $\mathrm{p}$ \\
\hline Continuous anger subscale & Sports & 101 & 23.84 & .57 & 15.682 & $0.000^{*}$ \\
& Non-sports & 99 & 20.83 & .50 & & \\
Anger subscale & Sports & 101 & 18.78 & .43 & 5.385 & $0.021^{*}$ \\
& Non-sports & 99 & 17.40 & .41 & & \\
Anger outward subscale & Sports & 101 & 17.15 & .39 & 2.072 & 0.152 \\
& Non-sports & 99 & 16.30 & .44 & & \\
Anger control subscale & Sports & 101 & 22.24 & .51 & 0.436 & 0.510 \\
\hline${ }^{*} \mathrm{P}<0.05$ & & & & & &
\end{tabular}

Table 3. Differences between gender and scales.

\begin{tabular}{llccccc}
\hline & Gender & $\mathrm{n}$ & Mean & SD & $\mathrm{t}$ & $\mathrm{p}$ \\
\hline Continuous anger subscale & Male & 101 & 22.63 & .56 & 0.527 & 0.469 \\
& Female & 99 & 22.06 & .55 & & \\
Anger subscale & Male & 101 & 18.44 & .43 & 1.277 & 0.260 \\
& Female & 99 & 17.76 & .42 & & \\
Anger outward subscale & Male & 101 & 17.39 & .45 & 5.171 & $0.024^{*}$ \\
& Female & 99 & 16.06 & .37 & & \\
Anger control subscale & Male & 101 & 22.25 & .52 & 0.473 & 0.492 \\
\hline${ }^{*} \mathrm{p}<0.05$ & & & & & &
\end{tabular}


Table 4. Difference between age and scales.

\begin{tabular}{llccccc}
\hline & Age & $\mathrm{N}$ & Mean & SD & $\mathrm{F}$ & $\mathrm{p}$ \\
\hline Continuous anger subscale & $18-20$ & 40 & 21.90 & .80 & 2.120 & 0.123 \\
& $21-23$ & 126 & 22.91 & .53 & & \\
& 24 and above & 34 & 20.79 & .77 & & \\
Anger subscale & $18-20$ & 40 & 17.70 & .63 & 2.145 & 0.120 \\
& $21-23$ & 126 & 18.54 & .39 & & \\
Anger outward subscale & 24 and above & 34 & 16.94 & .63 & & \\
& $18-20$ & 40 & 16.48 & .51 & 1.129 & 0.325 \\
Anger control subscale & $21-23$ & 126 & 17.04 & .40 & & \\
& 24 and above & 34 & 15.88 & .62 & & \\
& $18-20$ & 40 & 23.40 & .70 & 2.323 & 0.101 \\
& $21-23$ & 126 & 21.83 & .45 & & .96 \\
\hline
\end{tabular}

Table 5. Difference between number of siblings and scales.

\begin{tabular}{lcccccc}
\hline & $\begin{array}{c}\text { Number of } \\
\text { Siblings }\end{array}$ & $\mathrm{n}$ & Mean & SD & $\mathrm{F}$ & $\mathrm{p}$ \\
\hline Continuous anger subscale & 1 & 81 & 22.84 & .66 & 1.006 & 0.367 \\
& 2 & 87 & 21.71 & .54 & & \\
Anger subscale & 3 & 32 & 22.84 & 1.07 & & \\
Anger outward subscale & 1 & 81 & 17.91 & .42 & 0.134 & 0.875 \\
& 2 & 87 & 18.21 & .49 & & \\
Anger control subscale & 3 & 32 & 18.28 & .81 & & \\
& 1 & 81 & 17.09 & .50 & 0.535 & 0.587 \\
& 2 & 87 & 16.55 & .41 & & \\
& 3 & 32 & 16.31 & .75 & & \\
& 1 & 81 & 21.75 & .54 & 0.670 & \\
& 2 & 87 & 21.90 & .56 & & \\
\hline
\end{tabular}

Table 6. Difference between educational status and scales.

\begin{tabular}{llccccc}
\hline & Education Level & $\mathrm{n}$ & Mean & SD & $\mathrm{F}$ & $\mathrm{p}$ \\
\hline Continuous anger subscale & Primary School & 8 & 22.75 & 1.54 & 0.792 & 0.454 \\
& High School & 10 & 20.20 & 1.30 & & \\
& University & 182 & 22.45 & .42 & & \\
Anger subscale & Primary School & 8 & 18.13 & 1.78 & 0.026 & 0.974 \\
& High School & 10 & 17.80 & .95 & & \\
Anger outward subscale & University & 182 & 18.12 & .32 & & \\
& Primary School & 8 & 17.75 & 1.50 & 0.273 & 0.761 \\
& High School & 10 & 16.40 & 1.07 & & \\
Anger control subscale & University & 182 & 16.70 & .31 & & \\
& Primary School & 8 & 21.88 & 1.90 & 0.004 & 0.996 \\
& High School & 10 & 22.10 & 2.04 & & \\
& University & 182 & 22.01 & .37 & & \\
\hline
\end{tabular}

Starner \& Peters (24) found a positive relationship between persistent anger and anger-in, anger-out-of-sight, and anger control. As the anger of the students increased, the level of anger, anger, and anger control increased. There was a negative relationship between anger outburst and anger expression style and anger control expression style. As the level of anger outbursts and levels increases, the anger control of students decreases.
The difference between the anger subscale scores was significant for sporting stuation (Table 2). According to this, the individual who plays sports has a higher score on the subscale of anger than the individual who does not. According to this result, exercising plays an important role in suppressing the anger of the athletes. 
Table 7. Differences between maternal occupations and scales.

\begin{tabular}{llccccc}
\hline & Mother's Profession & $\mathrm{N}$ & Mean & SD & F & p \\
\hline Continuous anger subscale & Housewife & 159 & 22.26 & 0.45 & 0.266 & 0.767 \\
& Publice Sector & 20 & 22.20 & 1.16 & & \\
& Private Sector & 21 & 23.19 & 1.10 & & \\
Anger subscale & Housewife & 159 & 18.14 & 0.34 & 0.129 & 0.879 \\
& Publice Sector & 20 & 17.65 & 1.02 & & \\
Anger outward subscale & Private Sector & 21 & 18.24 & 0.75 & & \\
& Housewife & 159 & 16.63 & 0.34 & 0.594 & 0.553 \\
& Publice Sector & 20 & 16.55 & 0.73 & & \\
Anger control subscale & Private Sector & 21 & 17.67 & 0.94 & & \\
& Housewife & 159 & 21.87 & 0.39 & 1.961 & 0.143 \\
& Publice Sector & 20 & 24.00 & 0.99 & & \\
& Private Sector & 21 & 21.14 & 1.17 & & \\
\hline
\end{tabular}

Table 8. Differences between father profession and scales.

\begin{tabular}{llllllc}
\hline & Father's Profession & $\mathrm{n}$ & Mean & SD & $\mathrm{F}$ & $\mathrm{p}$ \\
\hline Continuous anger subscale & Self-employment & 82 & 23.10 & .71 & 3.669 & $0.027^{*}$ \\
& Publice Sector & 70 & 20.91 & .59 & & \\
& Private Sector & 48 & 23.17 & .63 & & \\
Anger subscale & Self-employment & 82 & 18.43 & .49 & 0.729 & 0.484 \\
& Publice Sector & 70 & 17.61 & .45 & & \\
Anger outward subscale & Private Sector & 48 & 18.25 & .66 & & \\
& Self-employment & 82 & 17.37 & .50 & 2.854 & 0.060 \\
& Publice Sector & 70 & 15.80 & .47 & & \\
Anger control subscale & Private Sector & 48 & 17.00 & .54 & & \\
& Self-employment & 82 & 21.88 & .53 & 0.393 & 0.676 \\
& Publice Sector & 70 & 22.41 & .68 & & \\
\hline
\end{tabular}

$* \mathrm{P}<0.05$

Table 9. Differences between mother's education and scales.

\begin{tabular}{|c|c|c|c|c|c|c|}
\hline & Mother's Education & $\mathrm{n}$ & Mean & SD & $\mathrm{F}$ & $\mathrm{p}$ \\
\hline \multirow[t]{3}{*}{ Continuous anger subscale } & Primary School & 134 & 22.39 & .49 & \multirow[t]{3}{*}{0.592} & \multirow[t]{3}{*}{0.554} \\
\hline & High School & 47 & 22.74 & .78 & & \\
\hline & University & 19 & 21.11 & 1.24 & & \\
\hline \multirow[t]{3}{*}{ Anger subscale } & Primary School & 134 & 18.28 & .38 & \multirow[t]{3}{*}{0.364} & \multirow[t]{3}{*}{0.695} \\
\hline & High School & 47 & 17.68 & .60 & & \\
\hline & University & 19 & 17.89 & .89 & & \\
\hline \multirow[t]{3}{*}{ Anger outward subscale } & Primary School & 134 & 16.75 & .38 & \multirow[t]{3}{*}{0.496} & \multirow[t]{3}{*}{0.610} \\
\hline & High School & 47 & 17.02 & .53 & & \\
\hline & University & 19 & 15.89 & .78 & & \\
\hline \multirow[t]{3}{*}{ Anger control subscale } & Primary School & 134 & 21.75 & .46 & \multirow[t]{3}{*}{0.744} & \multirow[t]{3}{*}{0.477} \\
\hline & High School & 47 & 22.27 & .65 & & \\
\hline & University & 19 & 23.16 & .99 & & \\
\hline
\end{tabular}

Lutwak et al. (2001), in a study investigating the relationship between shame and anger expression, have determined that the withdrawal of the anxious people has driven their anger into them (20). When the students who participated in the research examined the continuous expression of anger and anger; no significant difference was found between the variables of active sports making and sports type (3). 
The difference between the anger subscale and the anger control subscale scores was not significant (Table 2). Starner \& Peters (24) found a positive relationship between persistent anger and anger-in, anger-out-of-sight, and anger control. As the anger of the students increased, the level of anger, anger, and anger control increased. There was a negative relationship between anger outburst and anger expression style and anger control expression style.

The study's results showed that male and female had different different scores of continuous anger subscale, anger subscale, anger subscale and anger subscale scores (Table 3). According to this, the score of male sub-scale is higher than that of female subscale. It can be understood from this that men can express their anger more easily than women.

In a study investigating the relationship between shame and anger expression, Lutwak et al. have determined that the withdrawing people have turned their anger through repression (20).

In the study, the continuous anger subscale score was different for their father's profession. According to the results of the post hoc tests, the scores of the continuous anger subscale scores of the private sector and the self-employed of the fathers were the same, while the scores of the subscales of the continuous anger subscale of the fathers were lower than those of the public sector (Table 8). These results show that the private sector and self- the anger level of the children remains low (neither high nor low), and the anger of the people who work for the public parents can be low.

According to the father's occupation variable, the father's occupation, self-employed occupation and pensioner are more likely to feel anger because of the high levels of anger than workers and farmers, while the father occupational officers can suppress their anger due to high level of anger according to tradesmen, farmers, retired and self-, those who are self-employed by the father occupation, those who are employed by the workers, the farmers and the retired, and those who are retired by the father's profession are more likely to express their anger because of the high levels of anger outcasts compared to those who are father-occupied farmers, and those who are paternal workers are workers and artisans and those who are father- it can be concluded that the level of anger control is high and that they can keep their anger under control.

\section{REFERENCES}

1. Altıntaş E. Stress management. İstanbul: Alfa Publishing, 2003.

2. Averill JR. Studies on anger and aggression: Implications for teories of emotion. American Psychologist, 1983; 38: 1145-1160.

3. Aydın E, İnce A. Determination of continuous angers and anger expression styles students participating in sporting recreation activities. The Journal of International Anatolia Sport Science, 2016; 1(1): 36-55.

4. Ben-Zur H. Happy adolescents: Th e link between subjective well-being, internal resources and parental Factors. Journal of Youth and Adolescence, 2003; 32(2): 67-79.

5. Bıyık N. Examination of university students' loneliness feelings in terms of personal social characteristics, anger tendencies. Unpublished master's thesis, Anadolu University, Institute of Educational Sciences, Eskişehir, 2004.

6. Bostancı N, Çoban Ş, Tekin Z, Özen A. The way university students express anger according to sex. Crisis Magazine, 2006; 14(3): 9-18

7. Demir S, Kaya A. The effect of group guidance program on social acceptance levels and sociometric status of adolescents. Primary Education Online, 2008; 7(1): 127-140.

8. Deniz ME, Kesici Ş, Sümer AS. The validity and reliability study of the Turkish version of self-compassion scale. Social Behavior and Personality: An International Journal, 2008; 36(9): 1151-1160.

9. Dilmaç, B, Hamarta H, Arslan C. Analysing the trait anxiety and locus of control of undergraduates in terms of attachment styles. Educational Sciences: Theory \& Practice, 2009; 9(1): 127159.

10. Eisenberg S, Delaney DJ. Psychological counseling. (Translate: N. Ören, M. Takkaç). İstanbul: Ministry of National Education Publications, 1998.

11. Hamarta E. Problem solving and social problem solving of adolescents Investigation in terms of perfectionism. Primary Education Online, 2009; 8(3): 729-740.

12. Kısaç İ. The level of expression of anger and anger in university students according to some variables. Unpublished $\mathrm{PhD}$ thesis, Hacettepe University, Institute of Educational Sciences, Ankara, 1997.

13. Koç M. Adolescence period in terms of developmental psychology and general characteristics. Journal of Social Sciences Institute, 2004; 17(2): 231-256.

14. Mayer JD, Salovey P, Caruso DR, Sitarenios G. Emotional intelligence as a standart intelligence. Emotion, 2001; 1: 232242.

15. Lerner H. Anger Dance. 7. Issue. İstanbul: Varlık Publications, 89. (Translate: S. Gül), 2007.

16. Özer AK. Preliminary study of the style of constant expression of anger and anger. Journal of Turkish Psychology, 1994; 31: 26-35.

17. Özer Z. The world of emotion is anger. Science and Technical Journal, 1997; 354: 80-84.

18. Parman T. Family dynamics with adolescence and pathological mourning as a mourning period. Child and Youth Mental Health Magazine, 1998; 5(1): 40. 
19. Pavot W, Diener E. The affective and cognitive context of self reported measures of subjective well-being. Social Indicators Research, 1993; 28(1): 1-20.

20. Saçar B. Elementary school eighth grade students' anger response to friendship examination. Department of Educational Sciences, Master Thesis, Cukurova University Social Sciences Institute. Adana, 2007.

21. Savaşır I, Şahin NH. Assessment in Cognitive-Behavioral Therapies: Frequently Used Scales.Ankara: Turkish Psychological Association Publications, No: 9, 1997.

22. Soykan Ç. Anger and anger management. Crisis Magazine, 2003; 11(2): 19-27.

23. Spielberger CD. State-trait anger expression inventory. Orlando, Florida, FL: Psychological Assesment Resources, 1991.
24. Starner TM, Peters RM. Anger expression and blood pressure in adolescents. The Journal of School Nursing, 2004; 20(6): 335342 .

25. Sung KM, Puskar KR, Sereika S. Psychosocial factors and strategies to cope with youth are a rural Pennsylvania Higher School. Public Health Nursing, 2006; 23(6): 523-529.

26. Tambağ H, Öz F. Forms of expression of anger by adolescents living together with their parents and orphanages. Crisis Magazine, 2005; 13(1): 11-21.

27. Yavuzer H. Child and Crime. Puberty. 1. Issue. Golden Books Publishing House, 1982.

28. Yetim Ü. Individual happiness pictures from the society. İstanbul: Bağlam Publications, 2001. 